\title{
Coming to America: Iranians' Use of Telegram for Immigration Information Seeking
}

SARAH NIKKHAH, Department of Human-Centered Computing, Indiana University Purdue University at Indianapolis, Indianapolis, Indiana, USA

ANGELA P. MURILLO, Department of Library and Information Science, Indiana University Purdue University at Indianapolis, Indianapolis, Indiana, USA,

ALYSON LEIGH YOUNG, Department of Human-Centered Computing, Indiana University Purdue

University at Indianapolis, Indianapolis, Indiana, USA

ANDREW D. MILLER, Department of Human-Centered Computing, Indiana University Purdue University at Indianapolis, Indianapolis, Indiana, USA

\begin{abstract}
Purpose: This study examines Iran-US migrants' use of the most popular messaging application in IranTelegram - and shows how they use it to manage their migration information practices.

Design/Methodology/Approach: This study took a qualitative observation approach. Over the course of six months, over 80 hours of observations were conducted on Iran-US migration-related settings within Telegram.

Findings: This work identifies the information practices that emerge as users seek and share information related to Iran-US migration. Telegram plays a vital role across the immigration stages, predominantly in the premigration stage. This work also shows how the constraints and features of Telegram influence users' information sharing and seeking practices.

Practical implications: The findings support the implication that a social media platform that provides multiple ways to interact is likely to better support niche or unanticipated uses.

Originality: This study is the first of its kind to explore Iranian Immigrants information practices in the US. The immigration information practices observed during this study represent a valuable example of end-user appropriation within extraordinary constraints, which may be of use in other information-seeking contexts where dedicated or bespoke tools are impractical or ill-advised.
\end{abstract}

\section{KEYWORDS}

Information Seeking, Immigration, Online Communities, Iran, Telegram, Social Media

\section{INTRODUCTION}

Today, over 13\% of the United States population was born outside the country (Radford and NoeBustamante, 2019), and almost all US residents can trace their ancestry from other nations (Kennedy, 1964). Each year, more than 1 million immigrants arrive in the US (López et al., 2018). In the process, immigrants face multi-dimensional challenges. They must navigate bureaucratic processes, cultural differences, language barriers, and multi-dimensional information-related challenges. As a result, many immigrants use social media tools for information seeking and sharing. These social media tools help them to navigate rules, practices, and unwritten cultural expectations in their new home while maintaining a sense of cultural identity as immigrants (Borkert et al., 2009).

Iranians immigrating to the US face particular logistical and information challenges. The political situation between the two countries makes travel challenging, and the lack of diplomatic relations makes immigration tasks complicated. Even counting the number of Iranians in the US is fraught, although the best estimates suggest that between one and two million Iranians currently live in the US (Radio Farda, 2012). Many Iranians prefer not to identify themselves as Iranians in surveys(Mostashari and Khodamhosseini, 2000). Additionally, some immigrants in the US who are ethnic minorities in Iran prefer to identify themselves as part of their ethnic minorities such as Armenians, Jews, Kurds, Assyrians, Turkmen, Baloch, Arabs, Azerbaijanis 
(Mobasher, 2006). Finally, many Iranians prefer to identify themselves as Persians to distinguish themselves by Persian ethnicity or dissociate from the Islamic regime of Iran (Mobasher, 2006; Mostofi, 2003). In this extreme environment, reliable information about current situations and processes can be hard to find, and little is known about Iranian immigration information practices.

Furthermore, there is little Information Science research on how immigrants use social media technology throughout the whole process. Most prior research focuses on identifying the different sources of information or immigrants' use of technology at the post-immigration stage. However, as Caidi and colleagues have shown, immigrants' information seeking processes span multiple stages, from the pre-migration stage to the integrative stage (Caidi et al., 2008). Iranian immigrants present a unique opportunity because their Internet use is highly restricted: The Iranian government blocks many sites and applications popular in other countries, such as Facebook and Twitter (Frenkel, 2018).

In this study, we examined Iran-US migrants' use of the most popular instant messaging application in Iran, Telegram, and showed how migrants use it to create online communities to manage migration practices. We observed Telegram's role in migrants' information seeking and sharing behavior. The research team identified the interaction patterns and communication practices among users as they share knowledge and coeducate each other throughout the immigration process. Our findings show how Telegram plays a vital role in users' immigration experience, despite being an instant messaging application. We discuss the implications of using a messaging application as an immigration information tool, providing practical implications and opportunities for further research.

A note on terminology: in this paper, we use the term 'migrant' to refer to any individual moving to another country for an extended period, whether permanently or not. We include in this definition people who are contemplating such a move, are in the process of moving, and who have already moved. We provide more detail in the Methods section.

\section{BACKGROUND}

\subsection{Telegram Messaging Application}

Telegram is an instant messaging application, freely available on multiple platforms and featuring end-toend encryption. It provides services including voice calls, text messages, voice messages, video messages, stickers, and sharing photos and files of any type. As with WhatsApp, Telegram users authenticate with a phone number, but they can then create a Telegram ID and profile to share with others without having to share their phone number. See Figure 1 for a typical Telegram inbox.

Telegram differs in critical ways from traditional messaging apps. On Telegram, in addition to common one to one messaging features, there are other features including:

Public Channels where an administrator can broadcast information, which individual users can view but not respond.

Supergroups can have up to 100,000 members. Unlike Channels that only allow admins to send messages, all members can send messages and ask questions. These Supergroups are unique to Telegram, and function like a combination of a discussion forum and a chatroom.

Traditional Chat Groups that have fewer members than Supergroups, usually private with less than two hundred users, where all members can all send and receive messages. 
Telegram does not offer an official directory or in-app search mechanism to find topic-based groups or Channels, nor does it maintain a robust search history. Consequently, individuals must either know the exact Group, Supergroup, or Channel Link to locate it or be added by an Administrator. While this adds a layer of security, it makes use of Telegram potentially difficult.

\subsection{Why Telegram?}

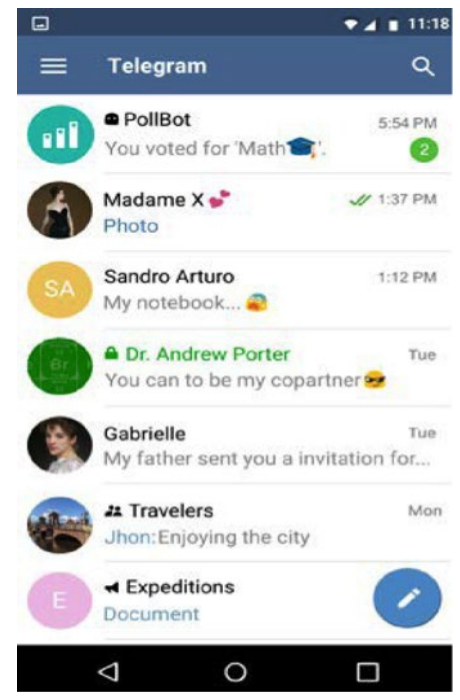

Figure 1. Image of Telegram

Application

At first glance, Telegram may seem an unusual choice of platform for studying immigration information seeking and sharing practices. However, for Iranian migrants, Telegram plays a crucial role in their immigration journey, for both political and technological reasons.

Telegram is one of the most widely used social computing platforms in Iran, and at the time of data collection was the most popular messaging application. At its peak, as many as 46 million Iranians used Telegram regularly - representing more than half the country's population and almost all of its 48 million smartphone users (Cox et al., 2009; Frenkel, 2018). In 2017, over 60\% of Iran's internet bandwidth was spent on using the Telegram application (ISNA, 2017). In 2013 almost half of the top 500 visited websites worldwide were periodically or temporarily blocked (Horvat, 2015). Widely accessible websites and social media platforms such as YouTube, Facebook, and Twitter have been permanently filtered in Iran (Khodabakhshi, 2018), and popular search engines such as Google and Bing are periodically blocked. Text messaging applications have a short lifespan in Iran before they are permanently or periodically filtered. Therefore, Iranians started using Telegram after the government blocked access to the other messaging applications, including Line, WhatsApp, WeChat(Alef, 2015), and finally, Viber (Entekhab, 2015; Tebyan, 2015). In the past year, Telegram has been periodically filtered and then outright blocked by the Iranian government, requiring Iranian users to find workarounds such as proxy servers and VPNs. Despite this, Telegram is still widely used by Iranians for communication (Askary, 2018).

Telegram features such as Supergroup and Channels made Telegram a unique social media platform in Iran. For example, while Viber groups have a limit of 50 members, Supergroups in Telegram can have up to 200,000 members(Golkar, 2015; Tebyan, 2015). Telegram allows file transfers of up to one gigabyte of data and is compatible with most modern operating systems, including iOS, Android, and Windows PCs. Telegram Channels specifically allow for broadcasting information to thousands of users. Therefore, many Telegram Channels are created for entertainment, news, advertising, and to broadcast a wide range of information (Azali, 2017, 2016; Golkar, 2015). Over 20 thousand Channels out of the 555 thousand public Farsi Channels on Telegram have at least 5 thousand members (Jafari, 2017). In an initial search, we also found evidence of robust immigration-related discussions occurring on Telegram, with some Supergroups seeing more than 1000 messages per day. Telegram shows how many people viewed a message on Channels; some posts in these 
immigration-related Supergroups reached more than 20 thousand views. This high usage made Telegram a great fit for us to study Iranian immigrant's information-seeking behavior.

\section{RELATED WORK}

\subsection{Information Seeking Online}

Information seeking in Library and Information Science refers to the process of actively seeking information from individuals' social networks or within technological and media contexts (Caidi et al., 2010). For example, in Ellis's model of information-seeking behavior (1989), the process of information seeking consists of six components: (1) Starting, activities used in the initial information search, (2) Chaining, following chains or threads of replies either backward or forward, (3) Browsing, casually looking for information on areas of potential interest, (4) Differentiating, using known differences such as the nature and quality of resources to identify best answers, (5) Monitoring, keeping abreast of developments in the area by regularly following particular sources, and (6) Extracting, activities associated with reviewing information related to a specific keyword or hashtag, and selectively identifying relevant content from these sources, such as sets of questions, series of hashtags, or keywords.

The use of social media for information seeking has been widely studied in Information Science. Within this body of work, researchers have examined the uses and benefits derived from social Q\&A sites (Panovich et al., 2012), online reviews (Antin et al., 2012; Cox et al., 2009), and social networking sites (Jeon et al., 2016), on topics ranging from temporary accommodation (Milano et al., 2011) to health (Lambert and Loiselle, 2007). When searching for information, people tend to "take small steps, using context as a guide" (Teevan et al., 2004), and social media applications provide a venue for such small steps within a culturally-sensitive context. Social Q\&A sites have been particularly successful, providing timely and relevant responses and often including various answers (Mamykina et al., 2011). These sites also encourage conversational questions that generate discourse and informational questions, which will create static resources over the long term (Harper et al., 2008).

Other research has examined the use of social network sites (SNSs), such as Facebook, as information resources. Lampe et al. (2012) found that people are not likely to engage in information seeking with Facebook friends, while Khojasteh and Fussell (2017) report that undergraduate students prefer to use group messaging rather than Facebook to gather information. When SNSs are used to seek information, research has shown that users do not use them for crowdsourcing, but rather for direct questions to people they perceive can provide the best answers (Forte et al., 2014). Further, Facebook was the preferred information source when individuals sought a specific audience, information needs were subjective, or they hoped for better personalization and contextualization in responses. With respect to immigration, research suggests that immigrants prefer to consult trusted individuals rather than official information sources (Adkins and Sandy, 2017). However, less is known about how information-seeking operates in the types of large open chats enabled by platforms such as Telegram.

\subsection{Immigrants'Use of ICTs \& Social Media}

Information Science scholars have studied the role of ICTs in the lives of immigrants, paying particular attention to the post-immigration experience. For example, Brown, Ayo, and Grinter (2014) studied how immigrant women self-reflect on their health and wellness, Burrell and Anderson (2008) studied the impact of technologies in the lives of Ghanian immigrants living in London, Charmarkeh (2013) studied the multiChannel post-migration practices of Somali immigrants in France, and Talhouk and colleagues (2016) studied opportunities to support prenatal health. Other Information Science researchers have looked at immigration from a community-level perspective. For example, Hirsch and Liu (2004) developed a system for language interpretation for an immigrant community with significant language barriers, and Guberek and colleagues (2018) studied the role of technology use by undocumented immigrants in the US.

Scholars in a variety of countries have studied immigration technology. For example, in a study of Korean settlement and information behavior, Suh and Hsieh (2019) found that different information needs of Korean immigrants are intertwined; however, health and legal information were vital. Focusing on social media, Information Science researchers have studied its impact on intercultural adaptation (Sawyer and Chen, 2012). Many scholars focus on how immigrants use social media to adjust to their new surroundings and culture while preserving a sense of cultural identity. Rao and Hemphill (2016), for instance, found that 
immigrants use Facebook to build a sense of local community in their new surroundings, gathering, and reifying professional networks. Researchers have also found that immigrants use social media to stay connected to their countries and cultures of origin - preserving a sense of migrant identity and collective memory (Borkert et al., 2009).

Information Science researchers have also studied the effects of mobile social messaging platforms on acculturation. For example, Chen (2018) and colleagues studied first-generation US Chinese immigrants' use of WeChat, a mobile messaging platform popular in their home country but barely known in the US. Results from several studies show that, for student immigrants, co-nationals tend to use these platforms to forge a shared identity post-migration (Oh et al., 2018; Oh and Butler, 2018, 2019; Worrall et al., 2019). Mitra and Evansluong (2019) argue that such use may, in fact, be inhibiting acculturation.

\subsection{Iranian Immigrants' Information Practices}

There are not many studies on Iranian information seeking and sharing practices; most of the previous studies concentrate on health information seeking and sharing. For instance, Nikbakht Nasrabadi and colleagues (2015) conducted interviews with Iranian women to explore their health information seeking and identified barriers for information seeking related to insufficient support from the healthcare system, feelings of shame, financial matters, incorrect opinions, and beliefs and incompetent health literacy. Two other studies concentrated on breast cancer and screening information behavior of Iranian immigrant women in Toronto (Vahabi, 2011) and California (Shirazi et al., 2006). Both studies found the need for health education on the importance of early screening of breast cancer to Iranian immigrants.

\subsection{Immigrants' Information Needs and Information Seeking Process}

Immigration settlement involves the processes and activities that immigrants undertake to adjust to their new country (Caidi et al., 2010). This process includes house hunting, education, and job-seeking (Hakim Silvio, 2006), English language improvement (Banerjee et al., 2018), learning about healthcare (Courtright, 2005), and banking(Shoham and Strauss, 2008). For example, Shoham et al. (2008) studied North American family immigrants to Israel and found that the fulfillment of information needs can facilitate the absorption of these immigrants to the new country. They provided information on types of information needs such as information on housing, banking schooling and health, and how language difficulties acted as a barrier and suggested a model for facilitating absorption and increasing the sense of belonging to the new setting. Khoir et al. (2015) conducted a mixed-method explorative study on Asian immigrants and categorized their information behavior concerning settlement in South Australia. They categorized the primary information needs of newcomers as personal, general, and official needs, and for immigrants in longer stages of immigrants, the needs shifted to full participation. They also provided information on information needs, information grounds, and information sharing activities of this population in their study.

Hossain and colleagues studied social media use in the South Asian diaspora in the US, characterizing the uses and gratifications and effects on the social capital of social media use post-migration (2017a, 2017b). Annemaree Lloyd and colleagues have extensively studied the relationship between information and social inclusion for migrants, especially refugees, forced to migrate to a third country (Kennan et al., 2011; Lloyd, 2020; Lloyd and Wilkinson, 2019). Alard and Caidi (2018) studied Filipino migrants to Canada and their information practices and showed how migrants' information practices change across geographical location and time through interactions within and across social networks and translocal information landscapes. 
The term affordances of technology translate to the potential actions a technology can enable or afford (Gibson, 2014; Hutchby, 2001; Norman, 2013). The researchers use the affordance lens to study the relationship between the capabilities of technology and the human actions to be taken in the context of use as a unit of analysis(Lee, 2010; Zammuto et al., 2007; Maier and Fadel, 2009; Faraj and Azad, 2012). There are few studies on the relationship between information seeking practices of immigrants and the affordances of the platforms they use for immigration information seeking. In addition, there are few studies that study how the hidden affordances of a text messaging application like Telegram are being identified and used by a young tech-savvy population(Arouzi and De Luce, 2019) in a social-media restricted context like Iran(Frenkel, 2018) to enable unanticipated actions like immigration information sharing and seeking on a messaging application platform.

\subsection{Model of Information Needs in Immigration Settlement}

To help guide our investigation into the information seeking needs and practices of Iranian Telegram users during the migration journey, we use Caidi et al.'s model of information needs in immigration settlement(Caidi et al., 2008). While there are many models of immigration, settlement, and acculturation, there are relatively few holistic theories of the role of information behavior in immigration. Caidi and colleagues (2010) explain the two dimensions for categorizing information needs. First, orienting information seeking, which focuses on the "daily habits that individuals engage in as a means of monitoring everyday events through various sources, particularly the media." Second, problem-specific information seeking, which focuses on "solving individual problems or performing specific tasks." In their model of information needs in immigration settlement, Caidi et al. (2008) describe the information needs of immigrants across four overlapping stages:

Pre-migration: activities that individuals undertake before immigrating to a new country. This stage includes information seeking from both formal and informal sources, such as government websites, immigration lawyers, and family and friends.

Immediate: seeking information to address any pressing need for survival once an individual has arrived in the new country and includes things like shelter, language instruction, and orientation to their new city.

Intermediate: information access to local systems and institutions, including long-term housing, healthcare, employment, and legal activities.

Integrative: the stage when individuals have adjusted to their new city. At this stage, the information needs become more diverse, including increased participation in political and civic activities. In this paper, this framework has guided the understanding of how Iranian immigrants to the United States use Telegram for information seeking and sharing.

\section{METHODS}

In this paper, we report findings from a qualitative observational study of Iranian migrant-focused social media practices on the Telegram application. The first author, who is an Iranian student in the US, has been a member of several migration-related Telegram Supergroups and Channels since 2015. As a reminder: Public Channels are places where an administrator can broadcast information, but users cannot post or reply; and Supergroups are chat forums that can support upwards of 100,000 members, where all members can post messages.

To begin the study, the first author actively sought out public Telegram Supergroups and Channels focused on the processes of moving from Iran to other countries. This was accomplished through searching on Google and 'snowball' approaches when the Supergroup or the Channel moderators shared links within Telegram.

In January 2018, observations began on five public Supergroups and two public Channels with more than 5,000 members. Throughout this first month of observations, the first author met with the research team every week to discuss initial findings and decide on selection criteria for the Supergroups and Channels. After this initial phase, the researchers decided that the first selection criterion would be only to study the public Supergroups and Channels; therefore, in this study, the researchers did not observe private Groups and Channels. The second criterion was that the Supergroups and Channels should be mainly focused on immigrating from Iran to the US rather than to other countries such as Canada, England, Germany. In addition, we included Supergroups and Channels for the university application and visa interview processes for Iranian 
students planning to study in US universities. However, we decided not to observe Supergroups made explicitly for professional topics such as writing an academic paper or discussing engineering or medical topics in Farsi. Therefore, the team decided to observe 24 additional Supergroups and six additional Channels that met the criteria. In summary, observations were conducted on 45 public Telegram forums, including 35 Supergroups and ten Channels.

Throughout the observation period, the first author regularly logged into the Supergroups and Channels and took notes on the general topics discussed and kept copies of selected examples captured in screenshots with their translations. This resulted in 150 pages of notes and approximately 80 hours of direct observation without participating in the conversations. All authors discussed the findings from observations to extract themes in hour-long weekly meetings during this period. During these weekly discussions, the researchers noticed the use of recurring keywords and hashtags and expanded the search to explicitly include posts with those keywords and hashtags to gain a more nuanced understanding of the process. The Supergroup and Channel observations were completed in June 2018.

To complement the observation data, the authors then searched these Telegram Supergroups and Channels for instances of specific concepts from immigration stages and information needs at this stages that are specified in (Caidi et al., 2010). Some of these concepts are immigrants' problem-specific information seeking, including housing information, language information, transportation information, and banking information (Caidi et al., 2010). Therefore, grounded in our observations and these information-seeking categories, we searched for problem-specific information-seeking keywords. We took notes and created memos around these targeted observations, and captured examples in screenshots. Examples were translated into English. In our first pass on the data, we used inductive open coding to identify general themes. The first author extracted and categorized themes from the data. These themes and categories were discussed among the authors iteratively and in different sessions. We then deductively coded the data using the four stages of immigration proposed by (Caidi et al., 2008).

A codebook was generated with 94 codes, including 66 codes under the preimmigration stage based on student-oriented codes. These preimmigration codes included "university-oriented questions," "Releasing graduation documents," "SOP," "Fund," "I20," "Application fees," and general preimmigration codes like "Embassy Interview," "Learning English," "Work Experience," "Travel Ticket," "Luggage and Travel Accessories," and "Power of Attorney to Others in Iran." The immediate stage included 17 codes such as "money and bank accounts in the United States," "Food," "Rent," "buy or lease a car," "Health insurance," "Social Security Card," and "Utilities." Lastly, 11 codes were observed as intermediate and integrate stages such as "steps to get an invitation for parents," "Passport and Naturalization," "Visa Extension or change of immigration status," "Work visas and Permanent residency (such as H1B and EB1 visas _ employment-based visas that usually students apply for them after graduation)" and "important immigration laws and news."

When topics crossed multiple categories, we re-examined them for context. Finally, we further analyzed the data to look more granularly for information seeking and sharing behaviors, and to examine the role of administrators as gatekeepers and the use of different telegram features.

We included temporary migrants in our study because students make up a large proportion of Iranians who move to the US (Allard and Caidi, 2018), many of whom seek permanent status upon completion of their degree programs. According to Caidi et al. (2010), temporary migrants share many commonalities with other immigrants, and their inclusion can shape a comprehensive understanding of immigrants' practices. Some of the individuals we observed in these Supergroups may never make it to the US; we include them in our analysis because at the time of observation, they were in the pre-migration stage.

\section{FINDINGS}


This section starts by describing information seeing practices on Telegram and features that enable these practices, such as Channels, Supergroups, and links. Then it outlines the administrators' roles in managing the community, and it finally characterizes the information practices observed on the Telegram application during this study based on Caidi et al. model of information needs in immigration settlement stages (Caidi et al., 2008).

\subsection{Information Seeking on Telegram: Channels, Supergroups, and Links}

The observations on Telegram Supergroups and Channels show how Telegram became a unique social media platform for sharing information around a wide range of immigration-related topics. The number of members in the Channels (between 2000 and 45,000) and Supergroups (between 500 to 11,000) in our observations is an indicator of the large-scale use of Telegram among Iranian immigrants to the US. Members could join these public Supergroups and Channels using the invite links. All the Supergroups and Channels in the study shared their links, usually accompanied by a description under the about section of their profile. Members could share the Supergroup link and bio with other people by merely copying and pasting them as a message on Telegram or even on the other different platforms such as on the web. Although the main feature of the application used by members was text messages, the secure file transfer service allowed immigrants to share different media such as images and documents on the platform.

Out of the ten Channels and 35 Supergroups, the majority of them (seven Channels and 24 Supergroups) were primarily characterized as relevant to preimmigration stages. These Supergroups and Channels provided discussions related to the US visa, such as student visa, research scholar visa, work visa, and family visa. Additionally, there were Supergroups regarding different US embassies such as the US embassy in Armenia or Turkey, and US university application exams such as Graduate Record Examination. The remainder of the Channels, three Channels, primarily focused on news in Iran and the US, including Iran-US Immigration news and general news of the US for Iranians in the US in Persian. Furthermore, the remainder of the Supergroups, 11 Supergroups, was specifically created for post-immigration purposes, such as Supergroups for Iranians in different states including California and Texas, Supergroups for changing the immigration status from student to work or acquiring other types of permanent status, Supergroups for application for other family members such as parents or spouses back in Iran, and Supergroups on marketing, job searching, finding roommates and renting apartments in the US.

The average number of messages shared on the pre-immigration Supergroups we observed was 270 per day per Supergroup. This number was much lower in the post-immigration Supergroups with about two messages per day per Supergroup. For example, in the pre-immigration Supergroups, on the date January $25^{\text {th }}$, 2018, there were 241 messages shared on a university application Supergroup and 63 messages in a Supergroup on US Visa in Armenia Embassy. On the same date, in the post-immigration Supergroups that we observed, there were five shared messages on the Texas state Supergroup, and one message shared on the California state Supergroup. For the channels, the number of views is a more useful metric of engagement than the number of messages; since in most of the Channels, we observed the number of messages shared was less than two messages per day.

Therefore, considering the lower number of messages that the Channels broadcast (usually important news and key points related immigration.), they have more number of members than Supergroups (2000-45000 members in the Channels compared to 500-11000 in the Supergroups) as people who do not want to be disturbed by receiving many notifications from Supergroups, choose to join the Channels and only receive essential information. The number of views on messages posted on the pre-Immigration Channels was higher than in post-immigration Channels that we observed. In the preimmigration Channels, the number of views was approximately 4500 views per message, but the average number of views for post immigration Channels was around 1000 per message. For instance, a message posted on January, $26^{\text {th }}, 2018$ on a pre-immigration Channel related to the US visa, had 6503 views, while a piece of news related to the travel ban, posted on January $25^{\text {th }}$, 2018 on a post-immigration Channel had 3182 number of views.

Overall, the public Supergroups and Channels for preimmigration purposes such as Visas and the US university application Supergroups and Channels had considerably more members and more interactions on a daily basis than public Supergroups and Channels focused on postimmigration. The below sections describe the use of each of the Telegram features by Iranian immigrants for information seeking and sharing. 


\subsubsection{Channels}

On Telegram, curators can use Channels for unidirectional information sharing with passive viewers. Iranian immigration-related Channel topics include Iranians in the US, visa types, green card applications, immigration institutions, study abroad, visa lottery winners, exchanging money, cities, and states in the US, and exams such as the Graduate Record Examination. The number of members in the Channels we observed were between 2000 and 45000. Messages in the Channel typically include newsworthy updates and answers to frequently asked questions. However, Channels are limited in that they can only support broadcasting. For more flexibility and to interact with each other, Iranian immigrants turn to Supergroup chats.

Figure2 is an example of a message broadcasted on one of the pre-immigration related Supergroups, which updates the users with the statistics of the US immigration Visa issuance in January 2018. Also, consider how the admin used the file-sharing feature of Telegram to broadcast the pdf file with the members. The number of views of this message reached to 4505. Another useful feature of Telegram Channels can be seen in this example. Members can forward a message easily from the Channel to another Telegram user or the other Telegram Supergroups, only by tapping the forward icon at the lower right corner of the desired message on the Channel. This forwarding Icon and the number of views on a message do not exist by default in private messaging or Supergroup chats(See Figure 2).

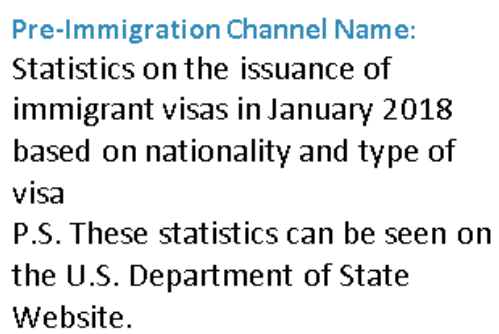

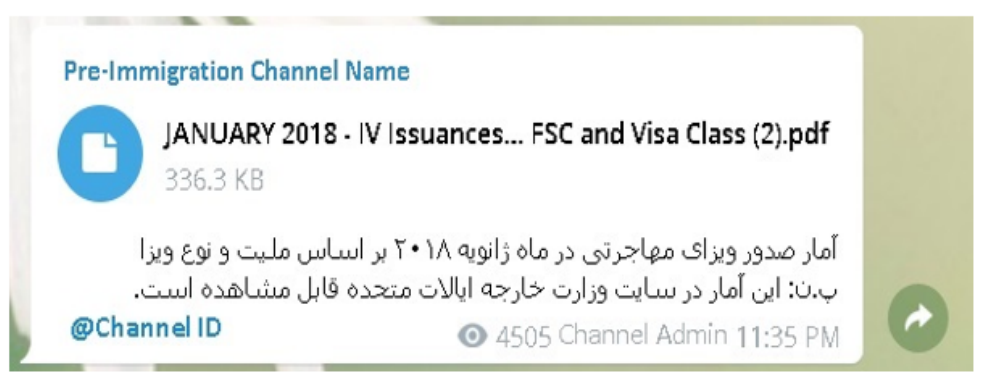

Figure 2 Screenshot of a message broadcasted to a pre-immigration Channel. The message contains a pdf file with visa issuance statistic for January 2018.

\subsubsection{Supergroups}

Telegram users use groups and Supergroups to have conversations around different topics and ask questions. Supergroups, which can handle up to 100,000 members, are used by Iranian immigrants to discuss topics of broad interest. The number of members in the Supergroups we observed was between 500 to 11,000 members. Controlling the information shared in Supergroups can be challenging. Only admins can delete other users' messages, and with some immigration Supergroups reaching 11,000 members, controlling the information shared in the Supergroups requires constant effort and social policing.

As with more traditional forums or community sites such as Reddit, Telegram allows administrators to 'pin' a post to the top as a 'Pinned Message.' These messages persist and allow administrators to convey information about the Supergroup, such as its topic, purpose, rules, or any other important or relevant message.

Another feature of Supergroups is that users can easily find and send direct messages to any other Supergroup member. However, since Telegram also operates as many users' primary mobile messaging platform, this introduces a new challenge compared to direct messaging functions on other discussion platforms. Messages from Telegram Supergroups are delivered directly to users' primary smartphones and mixed into the same inbox as messages from friends, family, and colleagues. Considering that members live in different countries, people may send messages at inconvenient times. As a drastic solution, we observed that some Supergroups used automated bots to deactivate the conversation during particularly inconvenient times temporarily. For example, a Supergroup related to the US Visa runs a bot that posts the following message to the Supergroup and disables the Supergroup during early morning hours in Iran. The bot posts the following message:

\section{"The group automatically turns off until six o 'clock in the morning. Use the opportunity and study previous conversations."}


Direct message spam can also cause problems. Managing spam and fraudulent direct messages were common concerns in the Supergroups we observed. For example, we observed a user reminding others about the Supergroup rules by posting a message to the group that indicated sending spam to users via direct message would result in their removal and ban from the group.

\subsubsection{Links}

Direct links are the primary Supergroup discovery mechanism in Telegram. Some Supergroups and Channels are searchable if users know the exact term, but not all Supergroups are easily found this way. In these instances, users must locate an out-of-band link to the Channel or Supergroup, which has been posted online, or they must receive the link from someone they know. While this helps to keep the Channels and Supergroups private, it also makes it challenging for users to find groups of interest. This process is complicated by the social rules surrounding linking. Many of the Supergroups we observed, explicitly prohibited link sharing. For example, one of the main rules of a Supergroup related to student application is:

"Any type of advertising, sharing the link to other groups, Channels, and irrelevant topics will be treated differently and, if repeated, the presence of the violator in the group will be prevented."

If someone ignores these rules and shares the link to another group without prior permission, the admin can restrict or block the person immediately.

\subsubsection{Private Channels and Groups}

Telegram does provide a privacy-focused option for conversations: private Channels and Groups. Most of the time, private Groups have fewer members. Private Groups and Channels do not have links, and users must be invited by the admins. Administrators require a user's ID to add them, which is negotiated via private message (See Figure 3).

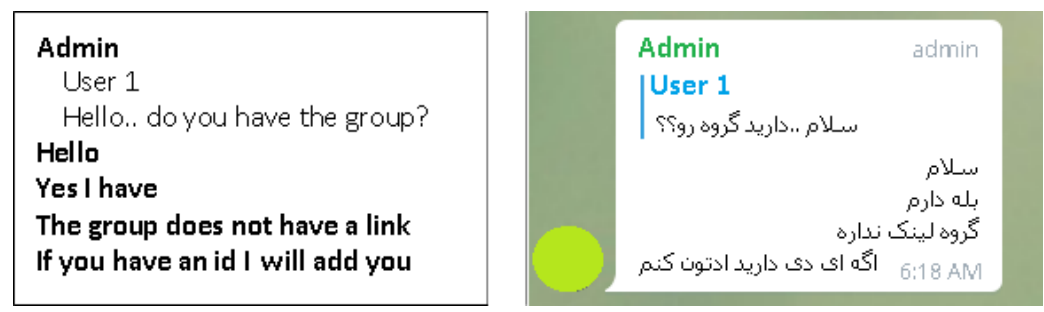

Figure 3. Screenshot of a reply from admin to a user who wanted to join a private group (English translation on the left).

While we did not directly observe these private Groups, we did see many occasions in the public Supergroups where users helped each other in finding private Groups by guiding them to the right person as evident in the example below (Figure 4):
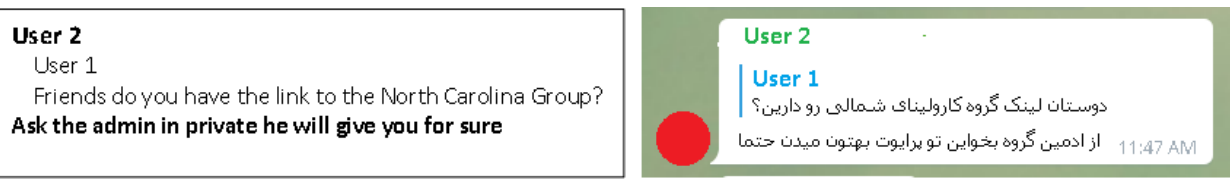

Figure 4. Screenshot of a reply from a user to another who wanted to join a private group (English translation on the left).

In our observations, we excluded the private Channels and Groups due to concerns about gathering consent from all members in these Groups and Channels. In future work, we plan to study private Channels and Groups more closely.

\subsection{Managing Community: Gatekeeping, Community Norms, and Expectations}

In the Telegram Supergroups we observed, administrators often acted as gatekeepers. Gatekeeping - the process of controlling information through a gate or filter - takes on new forms in online contexts. In social media settings, 'networked gatekeepers' not only select and broadcast information but also protect norms and maintain discussion within a given forum without unwanted external intrusion (Barzilai-Nahon, 2008). 
In their role as networked gatekeepers, administrators of Telegram Supergroups worked together to define rules and norms for acceptable community engagement and to reprimand those who did not follow such rules. They relied on pinned posts at the top of the screen to make these rules widely available and as visible as possible to the Supergroup. Although each Supergroup established its own set of rules or norms, four of the most common that emerged from our data were: (1) the exclusive use of Farsi language and Alphabet, (2) the exclusion of any displays of greeting or gratitude, (3) the restriction of link sharing, and (4) set operating hours for the Supergroup.

In terms of language use, administrators would request that all members post their messages in Farsi using the Persian Alphabet and write the whole text in one message (see Figure 5).
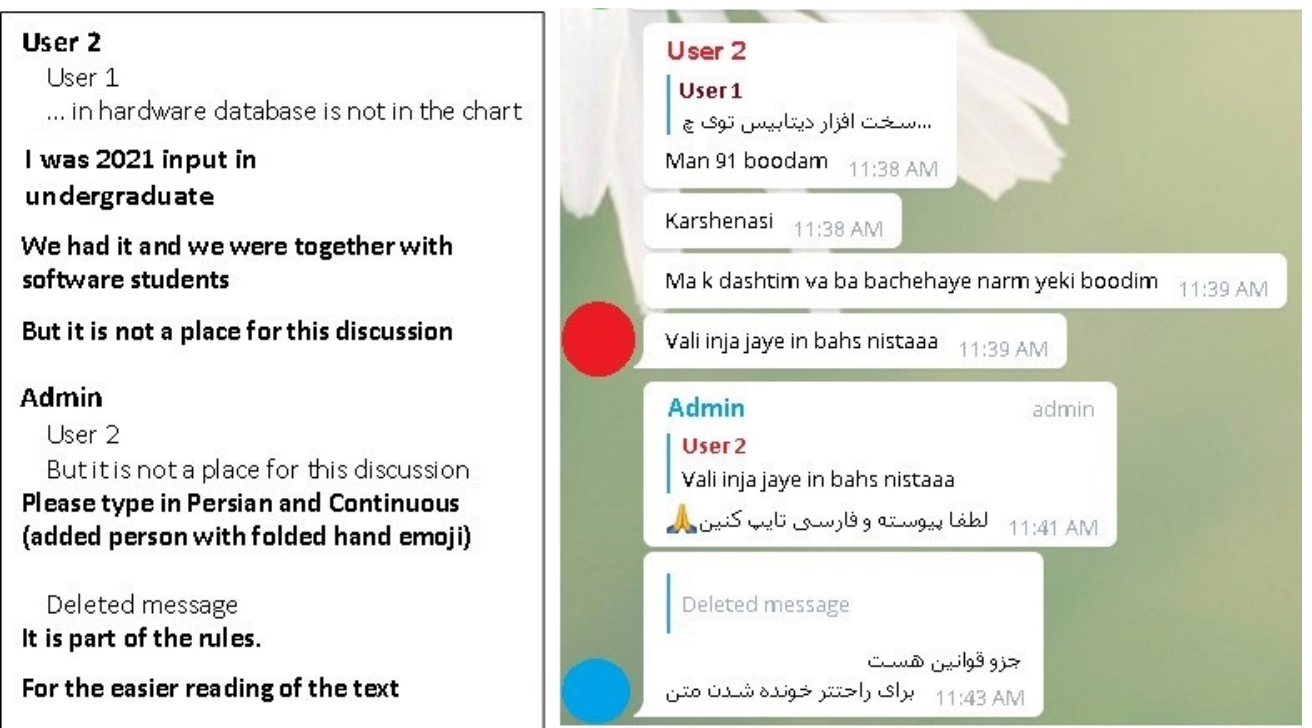

Figure 5. Screenshot of an instance where the admin asks a user to type in Farsi and put all text in one single message (English translation on the left).

In strict Supergroups, any messages posted using the Roman Alphabet, either in Farsi or English, would immediately be removed, and the user would be warned against subsequent infractions. One reason for the adoption of this rule could be for a straightforward search of specific keywords in one language, and another reason could be to ensure that all users have equal access to the information posted to the Supergroup.

Administrators also restrict the use of greetings or expressions of gratitude. In many of the Supergroups, the use of stickers/emojis to express emotion or messages of thanks were strictly prohibited (See Figure 6):
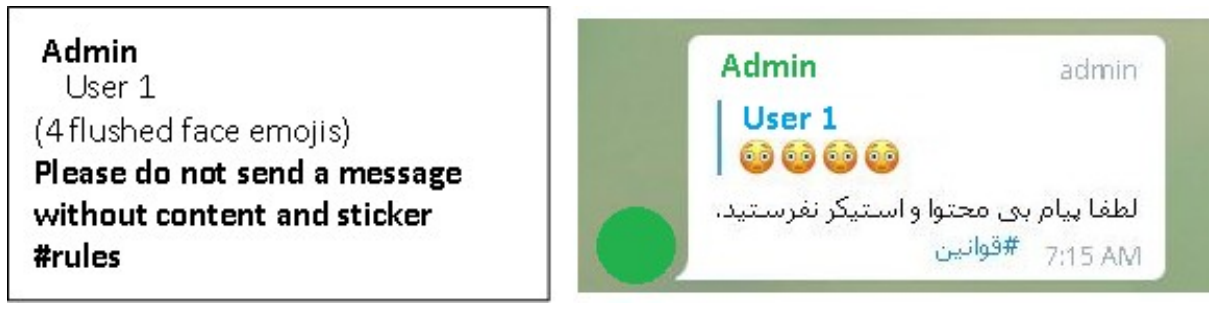

Figure 6. Screenshot of a reply from the admin asking a user to follow the rules (English translation on the left).

We speculate that the reason for this particular rule could be that they add much unnecessary noise to the conversations. As the Supergroups are often large, some with as many as 11,000 users, content that does not provide useful information could impact users' ability to find and consume information relevant to their search. Many of the Supergroups we observed explicitly prohibited link sharing. If someone ignored these rules and shared the link to another group without prior permission, the administrator could restrict or block the person immediately. 
While on the surface, such practices may seem counterproductive, as links are the only way to find a Supergroup, our observations suggest two main reasons for this rule. First, immigration Supergroups are competitive in terms of the number of members and their content. Second, such practices increase the overall security of the users in a Supergroup. This practice was particularly important for the Supergroups engaged in politically sensitive activities, such as immigration, where discoverability could potentially lead to grave consequences.

Finally, administrators also set strict hours of operation for their Supergroups. Outside of regular operating hours, the Supergroup is 'turned off,' and members are not able to post. For example, one Supergroup indicated that their hours of operation are between Six AM and 12 midnight, Tehran time. This practice is done to reduce the chances of disturbing people due to differences in time zones between Iran and the US during potentially inconvenient times, such as the middle of the night.

\subsection{Use of Telegram in the Stages of Immigration}

Iranians that we observed in the immigration and migration telegram Supergroups and Channels used the application for information seeking and sharing at different stages of immigration. In this section, we describe these information practices using the Caidi et al. (2008) framework of information needs across of the fourstage of immigration, pre-migration: immediate, intermediate, and integrative. We find that the public Telegram Iran-US migration Supergroups and Channels are predominantly used in the pre-migration stage. Within each stage, we describe the types of information needs and explain how information seeking and sharing happens (both at the individual level and social level).

\subsubsection{Pre-migration}

Most interactions we observed focused on the pre-migration stage. Telegram users gathered and disseminated information from formal and informal sources, including government agencies' publications and websites, immigration lawyers, family and friends, blogs, and online listservs to answer each other's questions and co-construct an understanding of the intricacies of the visa application process. The embassy interview emerged as the focal point of information work. Embassy interviews are crucial for Iranian immigrants to the US, as they take place in a third country since no US embassy exists in Iran. Missing a document or misunderstanding a procedure may mean the loss of significant time and money. Users educated each other about the varied and changing processes and shared embassy interview experiences and stories, assisting each other in the preparation of the required documentation and forms. Telegram users also used Supergroups to coordinate offline activities, such as traveling to specific embassies together.

\subsubsection{Embassy Interview}

Discussions about the embassy interview were spread across different Supergroups and Channels in Telegram. Much of the discussion focused on ordinary procedures related to the visa application process. Most Iranian immigrants to the US arrive on student and spousal visas (commonly referred to as F1 and F2), through the diversity immigrant visa program (green card lottery), or national interest waiver for individuals with extraordinary ability (EB1), and the discussions on Telegram reflect this. For example, one individual asked about the process of changing from one embassy to another and how it impacts the previous payment of the Student and Exchange Visitor Information System (SEVIS) fee:

\section{Hello friends, ... I paid SEVIS Fee for the embassy once for the Armenia embassy, but now I want to go to the Baku embassy. Should I re-pay SEVIS? Or, with a copy of the receipt of the initial payment and SEVIS number, can I do the same again?}

Other discussions were more focused, such as Supergroups dedicated to a specific embassy. For example, in a Supergroup dedicated to the United States embassy in Ankara, users gathered to discuss and understand the specific processes and quirks of that particular embassy. To help structure this discussion, the Supergroup's admin provided a template for how users returning from a trip to this embassy should describe their experience for the Supergroup. There have been some differences between the structure of the embassy trip for each of these Supergroups, but the main rules were fixed and standard in most of these Supergroups. This local norm allowed Supergroup users to build a shared understanding of the essential factors in the embassy interview, particularly factors which could affect the result of their interview. For example, one user commented: 
Hello friends. My experience before arriving at the embassy and talking to the

officer was the same as other friends... The officer was very nice, and the

interview did not last even 5 minutes.

In cases of rejection, the discussion often focused on how to prevent rejection for the next interview. Not all members were willing to share openly; in these cases, they would send their experience to the Supergroup admin, who would then anonymize their experience and post it in the Supergroup.

These structured posts and their resulting discussions allowed prospective immigrants to understand the process and become acculturated to the Supergroup. Such structure was especially crucial at the beginning of academic terms, as the Supergroups experienced an influx of users seeking information on student visas. Indeed, the high percentage of student visa applicants meant that many of the Supergroups operated in a cyclical fashion, whereby a batch of new members would join near the start of a school year or new groups would be created to support the new bunch of applicants.

Users would also use Telegram to crowdsource information on embassy interview availability, often asking for advice on which embassies have open slots during specific periods. In other cases, users who needed an immediate interview would try to coordinate with others who were either considering canceling or moving their appointment to a later date, as exemplified in this quote: "If anyone wanted to cancel or change their time for two people, send me a private message, please."

To further assist with coordination activities, Supergroup administrators created polls to coordinate group travel to an embassy. For those individuals scheduled to travel within a specific time frame, the administrator would task one member to create a small private group where they could discuss travel plans and share notes on interview preparation.

\subsubsection{Embassy Interview Documentation.}

A substantial portion of the discussions around the embassy interview focused on required documentation. Users would pose questions and share information on which documents were required by immigration officials and in which format. For example, one user asked about translation requirements:

"Hello. Is it sufficient for the translated documents for the embassy to have an interpreter's seal, or the judiciary must confirm too?"

Compiling the appropriate documentation in advance was a particular concern for Iranians seeking to migrate to the US because failing to meet such requirements the first time could result in lengthy and costly delays. Recall that Iranians have to travel to a third country to complete the embassy interview, as no US embassy exists in Iran.

\subsubsection{Navigating Legal Requirements.}

Once a user receives visa approval from a US embassy, their information seeking needs shift to other premigration considerations. Of utmost importance is working through a series of legal requirements before leaving the country. Unique to Iranians is the need to set up a power of attorney. This is someone within the country, typically an immediate family member, who can sign for or request documents on an individual's behalf. Having this in place eliminates the need for individuals to return to Iran to manage issues personally. This includes making arrangements for female family members. Iranian women are required to obtain written permission from a male relative, typically husband or father, to travel abroad or renew their passports. Users encouraged each other to have such documentation in place prior to departure to avoid any issues. For instance, if a woman's passport expires while her husband is abroad, she will not be able to renew it until he returns to the country and grants permission. This is an example of when a user replies to someone who asks about what should be noted in the power of attorney:

Hello. If you have a spouse or you are planning to have a spouse, definitely

tell the attorney to mention spouse matters because you will seriously face issues, and most attorneys don't mention this.

Then, in reply to what are spouse matters, he says:

For instance, your wife is in Iran, and you are in the US, and for any kind of reason she needs your permission and because it is not mentioned in the power of attorney the person who has the attorney cannot do anything and you need to go to the consulate for [writing] an agreement letter... 
Additionally, except for students who can obtain a waiver, Iranians leaving the country are required to pay a departure tax. The amount of this tax fluctuates over time, and the instructions for paying the tax are often unclear. Users used the Supergroup to obtain information on current pricing and crowdsource instructions on where and how to pay the tax, as can be seen in this exchange:

Q: Hello... some friends said there is no need to pay the departure tax. Is that real? For someone who is not yet a student and is going for the embassy interview?

A: Even for the students, the departure tax is waived after many bureaucratic paper works, let alone the ones who are not students. I know to this extent, but if you want to make sure to call the passport department. In addition, thank god the tax is 75 [they say 75, but they mean 75000].

Here, the admin forwards a message from another immigration Channel with the link to where the user can pay the tax online.

A: Pay the departure tax online from the site below: https://tollpayment.sadadpsp.ir//home.

\subsubsection{Immediate Stage}

The immediate stage focuses on urgent needs upon arrival, including immediate accommodation for the early days after arrival, understanding the intricacies of government and essential services such as social and healthcare services. The use of Telegram in the immediate stage revolved around pressing needs that new immigrants have to contend with for their survival in their new country. One of the most important needs was finding temporary accommodations. Supergroup members used the platform to seek advice on how to locate such accommodations. Common advice was to find Iranians already settled in the new city who could provide temporary lodgings.

In some cases, users would post a call for volunteers to host newly arrived Iranian immigrants, as can be seen in the following example:

If you live in Boston and volunteer to give new travelers any kind of assistance

(from welcoming at the airport and helping to move up to one or two nights in your home), please complete this form. Your help will not be forgotten for passengers who have endured extreme stress and pressure.

If none of these options were available, users would advise they seek temporary accommodations in a hotel or lodging service such as Airbnb until they could find more permanent housing.

Once temporarily settled in the US, Iranian immigrants' information needs shifted focus to understanding the intricacies of government and essential services, such as obtaining a social security card and selecting medical coverage. For social security, users asked questions about the length of time it takes to receive the social security card and whether it would automatically be sent with the green card or if they will have to apply for it separately:

Q: Hello friends, for Social Security, do we need to go to the Social Services offices to fill out their form, or will they send it to us with Green Card?

A: It's better to go.

Others asked how to change their address with social security once they have found permanent accommodations.

As the US healthcare system is much more complex and costly compared to Iran, users frequently asked questions about essential criteria they should consider when selecting a medical and dental plan. Common advice was to seek out insurance with more coverage than cheaper insurance and to record conversations with vendors as they often do not know the exact details of what a plan covers. For example,

If you want to buy dental insurance, be sure to tell the salesperson that you want to record the sound, and if the information is given to you is wrong, the salesperson is responsible for exchanging the wrong information.

\subsubsection{Intermediate and Integrative Stages}

The intermediate immigration stage focuses on information access to local systems and institutions, whereas in the integrative stage, individuals have adjusted to their new city and seek more diverse information, such as how to participate in political and civic activities. For individuals in the intermediate stage, the complicated relationship between Iran and the US raised concerns among users about travel outside the US. 
This was particularly the case for users on non-immigrant visas, namely students. Although the US, under the Obama Administration, instituted a multiple entry visa for Iranian students, many choose not to leave the US for fear they will be denied re-entry. Consequently, users often sought experiential information from others who had decided to travel on the multi-entry visa:

Hello, have anyone recently left on multi F1 visa?

Indeed, this was such a concern that users created a Telegram Supergroup specifically dedicated to discussing international travel.

Once they have arrived and settled, the questions related to transportation shifted from immediate transportation such as Uber and Lyft to understanding how to obtain a US driver's license, including required documentation, cost, location, and length of time to receive the license. Users asked about whether a state license could be used to drive across state lines. Users also asked about the processes for renting a car and whether it was possible without a credit card and about car insurance coverage, such as whether insurance covers a cracked windshield:

\section{A piece of stone fall into my front windshield and left a small crack. Does the insurance cover? If not, where is the best place to get the front windshield, and what is the price? I would appreciate if you guide me}

In this stage, users asked questions about more permanent accommodations. We saw users seeking out potential roommates to share housing. Users sought information on the processes of obtaining a loan or mortgage to purchase a property. This included asking questions about how much one could expect to get for a loan and at what interest rate. One user shared that:

"Your income determines the amount of the loan. Your credit rate determines how much your interest is."

In the integrative stage, users' banking information needs shifted focus to the processes for opening a bank account in the US and how to transfer money between the US and Iran. They also asked about the differences between credit and debit cards, bank loans, mortgage, or credit cards and information about banking tools, such as PayPal.

\section{DISCUSSION}

In this study, we found that users used public Telegram Channels and Supergroups almost exclusively for problem-specific information seeking, and we saw little evidence of a developing community of practice. Overall, administrators and users alike worked hard to maintain a practical and coherent discussion focused specifically on tangible issues relating to immigration information needs.

\subsection{Problem-specific Information Seeking}

Migrants' interactions in the public forums were grounded almost exclusively in specific issues or problems related to the immigration process. The questions users asked and information that was provided focused on solving individual problems or performing specific tasks. In particular, much of the information seeking focused on the Embassy interview. Due to the tenuous relationship between Iran and the United States, there is currently no US Embassy in Iran. This means that Iranians must travel to another country, such as Turkey or the United Arab Emirates, for their interview.

We did not observe the same number of interactions related to intermediate and integrate stages of immigration in these public Supergroups and Channels. Some notable exceptions were for university students who continued to use Telegram to learn about restrictions on traveling outside the US on multi-entry visas, and for information on internships and permanent job opportunities in the US. Therefore, including migrants entering on student visas in this study helped us show there exist some differences in terms of problem-specific information seeking between distinct classes of entry into the US, as suggested by Caidi et (Amirani, 2012)al. (2008). For those who immigrated to the US as permanent residents, information seeking in these later stages focused mainly on obtaining loans or mortgages to purchase a property. Additionally, some users who had reached the integration stage participated in the Supergroups by sharing their expertise and experience with individuals in the early stages of immigration.

However, on the whole, interactions in the Supergroups and Channels we observed were highly focused on the earlier stages of immigration. We suggest that one reason for this could be because once they have moved to the United States, they gain access to a broader range of social computing technology and online 
resources than what was available to them in Iran. It may also be the case that users' Telegram use shifts from public Supergroups to private Telegram Groups related to their new surroundings or other post-migration topics. We saw indications of this as users requested or discussed joining location-specific Groups (such as the discussion in Figure 4). This is an area we hope to investigate in our future work.

\subsection{I'm Not Here to Make Friends}

The public Telegram Supergroups and Channels we observed were generally devoid of the sorts of community-building social interactions found in other online forums. In our observations, we saw little evidence for the formation of online communities of practice. We looked specifically for common indicators of social bonding, such as in-jokes or another in-group signaling, phatic communication, identity presentation through avatars or status messages, off-topic chat, or other indicators of developing friendships. In other words, nobody seemed to be coming to these Supergroups to 'hang out.' Indeed, Supergroup administrators and users alike seemed determined to maintain these Supergroups as information seeking venues exclusively. Administrators 'pruned' discussions of distractions, such as expressions of gratitude or emojis (when not connected to an information post). Users also appeared to self-censor. For example, in the discussion seen in Figure $\underline{5}$, a user begins to share an anecdote about an experience in undergrad, then stops themselves by saying, 'but it is not a place for this discussion.'

Finally, political discussion or mentions of the current US administration were almost nonexistent, which is notable given the fractious climate both within and between the two countries. We suspect such political activities likely occur on Telegram, whether within users' existing friend groups or in other more private settings such as private Telegram Groups. However, it is still notable that the public Supergroups are so tightly focused on information seeking to the exclusion of community building.

\subsection{Interface features and patterns of use}

Telegram plays a unique role in the Iranian's information practices overall. Recall that Iranians use Telegram for multiple purposes, which in other countries might be split across applications such as iMessage, Google Hangouts, Facebook, and traditional forums. Our findings show that this complex relationship between Telegram and Iranian society extends to immigration, and that Telegram's unique features create an immigration information-seeking environment unlike others described in the literature.

Telegram's unique take on Supergroups and Channels allowed for a considerable number of members to communicate about a topic. Channels specifically provided the opportunity to broadcast important news and information on immigration to a large audience, and these Channels were often used in concert with Supergroups. For example, some Supergroup administrators used Channels to broadcast a summary of the messages or important messages from the Supergroups to the Channels. Telegram's Supergroup and Channel discovery process - invite links - made search more complicated but allowed lateral movement (such as recommending a related Supergroup or Channel) quite easy. Media sharing features allowed migrants to share different media, such as images and documents on the platform. While we did not observe many videos or audio messages being shared, we did observe many instances of sharing a photo and asking questions based on that or sharing photos to broadcast information in Channels. While the search feature was not always helpful in finding relevant Groups or Supergroups, users in the Supergroups we observed frequently discussed searching for specific posts within a Supergroup using the search feature. Also, Telegram allowed administrators to enable rules, use Telegram bots, delete specific messages, or remove members to ensure the adherence to the rules. Such gatekeeping practices on supergroups are in line with practices mentioned in Barzilai-Nahon's review work on gatekeeping (2009).

\subsection{Reflecting on the immigration stages}

We found that most of the Iranian immigration-related communication on public Supergroups and Channels consisted of information seeking during the pre-migration stage. There are many potential reasons for this. One potential reason might be that Iranian immigrants quickly switch to local social media platforms postmigration. A similar effect has been seen in studies by Allard and Caidi (2018). It may also be the case that Telegram use continues post-migration, but switches to private Groups and private messages, which we were not able to observe. Oh, et al. showed how this happens for Chinese college students in the US (Oh et al., 2018; Oh and Butler, 2018, 2019), and in future work, we would like to study Iranian immigrants post-migration through a similar interview method. 
However, while most of the interactions we observed fell into the pre-migration stage, we still saw Telegram being used across the stages and the different locations. The different information-seeking practices and interactions that we observed reinforce that migration is not a single step, and in the case of Iranian migrating to the US, it is not merely traveling from one country to another. Instead, our findings support Allard and Caidi's work (2018) and show that migration involves complex information processes that vary across different stages and different locations.

For instance, we have seen how the admins used bots to set strict hours of operation for their Supergroups due to disturbances caused by the differences in the time zones. In addition, we described how most conversations in the Supergroups for the US embassies in Turkey, Armenia, Dubai were concentrated on concerns around visa and documentation required for the interview, but there were enough differences between these countries that they each had their own separate Supergroup. For instance, they had different interview schedules availability, their countries have different currencies, and reservations for temporary accommodation and transportation in each of these countries were different from the other one.

In the post-immigration Supergroups, such as California or Texas Supergroups, the conversations were different from pre-immigration and ranged from initial needs such as food, accommodation, and transportation to finding a job, and changing immigration status in the US. Moreover, we also observed differences within these Supergroups as well. For instance, we observed more interactions and more instances of seeking roommates and accommodation in the California Supergroups compared to the Supergroups for the other states. This is in agreement with the fact that the Iranian population is more concentrated in California State (Amirani, 2012).

These findings together show how a social media platform, like Telegram, can facilitate the interrelations of information within and across different geographical locations, and can flourish the connecting nature of immigration by providing a platform for immigrants at different localities to shape Supergroups and Channels and use different forms of information exchange to stay connected in spite of geographical distances, political borders, and different time zones.

\section{PRACTICAL IMPLICATIONS}

Telegram is far from an ideal immigration information management tool. In our observations, we saw that users could not smoothly perform tasks one might expect, such as building knowledge bases or setting advanced privacy permissions. Information was frequently lost as newer messages crowded out potentially important posts, and the lack of threaded replies meant discussions quickly got muddled. However, given the political constraints on technology access in Iran (Smith, 2013), and the sensitive nature of immigration between the two countries, we do not recommend the design of new dedicated immigration information seeking and sharing technologies for this population.

Instead, our findings support the implication that a social media platform that provides multiple ways to interact is likely to better support niche or unanticipated uses. Indeed, the designers of an instant messaging platform never anticipated this particular use; however, Telegram's wide and rich feature set enabled such appropriations. Features such as 'Supergroups' and the unique link- sharing privacy model allowed users to construct and socially enforce rules. Therefore, Telegram application with all its constraints as a messaging application afforded certain resources and features that made it a useful tool for immigration information practices. In this study, we described how some of the features of Telegram, such as Channels, Supergroups, Links, and bots, supported unintended affordances for Iranian users to shape large groups and information resources where they could share their up-to-date knowledge related to immigration to the US with each other. In addition, this study suggests that when access to other social media is restricted (Frenkel, 2018), to stay social-media-savvy (Arouzi and De Luce, 2019), the users might better identify the hidden or unknown affordances of the technology in use, such as Telegram in Iran, and use that technology for purposes beyond its main design aims and intended affordances, such as merely sending text messages.

Furthermore, Supergroups made creative use of Telegram's "bot" framework, using bots to enforce group rules and norms. Together, these workarounds allowed users to seek out, share, and collaboratively construct information about a confusing and ever-changing process. Taken together, the immigration information practices we observed during this study represent a useful example of end-user appropriation within extraordinary constraints, which may be of use in other information seeking and sharing contexts where dedicated or bespoke tools are impractical or ill-advised. 
While Telegram has not been designed for immigration management practices, many of the Telegram features could be transferred for the design of larger immigration platforms or in improving existing immigration-related platforms. For instance, when designing for a large group of immigrants, we can consider factors such as no limitation on the number of members in a group and the link-sharing feature to provide immigrants more privacy and easy access to equal information, service, and give them a voice. In addition, the findings suggest a system that is multi-platform and has a link-sharing feature allows members to join simply using the link from their preferred device. Such a system could also have a voting feature where immigrants can vote for their rights and discuss different needs with other immigrants from their countries.

The feature to broadcast information to a wide range of audiences can be useful as an extension to the current platforms to provide information for immigrants. For instance, the USCIS website can use this feature to let immigrants choose to follow or subscribe to immigration news related to their country or related to their specific cases, such as Student Visa or Green Card Application. They can choose to follow specific Channels where USCIS broadcasts updated information on a daily, weekly, or monthly basis. All the information is available on the US government website, but they can choose to receive these messages in case there are new updates or changes related to their specific status.

Telegram could also better support networked gatekeeping by adding customizable features for Supergroups and Channels to facilitate the admins' tasks such as removing "thank you" notes, stickers, music, or the links to the other Supergroups. Some of these might be accomplished by programming bots within these Supergroups. Currently, Iranian users of these Supergroups must search specific keywords and read all the messages, including those keywords that might not necessarily address their questions. Therefore, having a data management feature such as the ones on windows folders or box folders to cluster and categorize information based on stages, keywords, and categories can be helpful to immigrants when they need to locate specific information in the Supergroups and Channels.

\section{LIMITATIONS \& FUTURE WORK}

Our study was limited by several factors, including methodological and political challenges. First, the observation reported here is based on a collection of Channels and Supergroups we were able to find but may not represent the totality of Iranian immigration information activities on Telegram. Second, we conducted our observations during a time when Telegram was at least partially filtered, which may have affected user behavior. In the future, we plan to supplement this qualitative observation with interviews and quantitative data science approaches to better characterize the prevalence and relative importance of the various topics uncovered during this study. We also plan to inspect the technology used during the post-immigration phase through conducting interviews and observing private Telegram Groups for Iranians in the US.

\section{CONCLUSION}

In this paper, we contribute an understanding of the ways that Iranian immigrants to the US use Telegram, an instant messaging application, for information seeking and knowledge sharing about the US immigration process. In particular, we illustrate the ways that Telegram supports and does not support specific information needs during the four stages of immigration, as defined by Caidi and colleagues (2008). We conclude by suggesting that while imperfect, Telegram enables users, who have limited access to other informational and social resources, to collectively and effectively learn about the immigration process. They do this by establishing community norms and creating technical workarounds to make the most out of the platform

\section{FUNDING}

This research did not receive any specific grant from funding agencies in the public, commercial, or notfor-profit sectors.

\section{REFERENCES}

Adkins, D., Sandy, H.M., 2017. Information seeking among latinos in the midwestern United States. Proc. Assoc. Inf. Sci. Technol. 54, 483-486. https://doi.org/10.1002/pra2.2017.14505401052 
Alef, 2015. Line, Whatsapp, Tango Filteration. URL http://old.alef.ir/vdcb5sb50rhbsap.uiur.html?255426

Allard, D., Caidi, N., 2018. Imagining Winnipeg: The translocal meaning making of Filipino migrants to Canada. J. Assoc. Inf. Sci. Technol. 69, 1193-1204. https://doi.org/10.1002/asi.24038

Amirani, S., 2012. Amirani, Shoku (29 September 2012). "Tehrangeles: How Iranians made part of LA their own". BBC News. Available at: https://www.bbc.com/news/magazine-19751370. BBC News.

Antin, J., de Sa, M., Churchill, E.F., 2012. Local experts and online review sites, in: Proceedings of the ACM 2012 Conference on Computer Supported Cooperative Work Companion, CSCW '12. ACM, New York, NY, USA, pp. 55-58. https://doi.org/10.1145/2141512.2141541

Arouzi, A., De Luce, D., 2019. Tech-savvy Iranians stay connected on social media despite regime restrictions. nbcnews.

Askary, H., 2018. Survey: Despite its ban Iranian users stay on Telegram. Teleram Ban.

Azali, M., 2017. Have Iranian Telegram Channels Really Generated \$23.3M in Revenue? TechRasa. URL http://techrasa.com/2017/01/17/iranian-telegram-channels-23-3m-revenue/

Azali, M., 2016. Messaging Apps impact on Iran. TechRasa. URL http://techrasa.com/2016/01/13/impact-telegram-iran/

Banerjee, R., Liu, L., Sobel, K., Pitt, C., Lee, K.J., Wang, M., Chen, S., Davison, L., Yip, J.C., Ko, A.J., Popovic, Z., 2018. Empowering families facing english literacy challenges to jointly engage in computer programming, in: Proceedings of the $2018 \mathrm{CHI}$ Conference on Human Factors in Computing Systems, CHI '18. ACM, New York, NY, USA, p. 622:1-622:13. https://doi.org/10.1145/3173574.3174196

Barzilai-Nahon, K., 2009. Gatekeeping: A critical review. Annu. Rev. Inf. Sci. Technol. 43, 1-79.

Barzilai-Nahon, K., 2008. Toward a theory of network gatekeeping: A framework for exploring information control. J. Am. Soc. Inf. Sci. Technol. 59, 1493-1512. https://doi.org/10.1002/asi.20857

Borkert, M., Cingolani, P., Premazzi, V., Kluzer, S., Hache, A., 2009. The state of the art of research in the EU on the uptake and use of ICT by immigrants and ethnic minorities-EU science hub-European Commission (EUR - Scientific and Technical Research Reports No. EUR 23991 EN OPOCE LF-NA-23991-EN-C), EUR - Scientific and Technical Research Reports. European Commission.

Brown, D., Ayo, V., Grinter, R.E., 2014. Reflection through design: immigrant women's selfreflection on managing health and wellness, in: Proceedings of the SIGCHI Conference on Human Factors in Computing Systems, CHI '14. ACM, New York, NY, USA, pp. 1605-1614. https://doi.org/10.1145/2556288.2557119

Burrell, J., Anderson, K., 2008. 'I have great desires to look beyond my world': Trajectories of information and communication technology use among Ghanaians living abroad. New Media Soc. 10, 203-224. https://doi.org/10.1177/1461444807086472

Caidi, N., Allard, D., Dechief, D., 2008. Information Practices of Immigrants to Canada - A Review of the Literature 66, Research Contract Commissioned by Citizenship and Immigration Canada (CIC) and Metropolis.

Caidi, N., Allard, D., Quirke, L., 2010. Information practices of immigrants. Annu. Rev. Inf. Sci. Technol. 44, 491-531. https://doi.org/10.1002/aris.2010.1440440118

Charmarkeh, H., 2013. Social Media Usage, Tahriib (Migration), and Settlement among Somali Refugees in France 29, 12.

Chen, H., Butler, E., Liang, X., 2018. Facilitating or Impeding Acculturation: A Qualitative Study on Mobile Social Messaging in First-Generation Chinese Immigrants' Everyday Lives. J. Intercult. Commun. Res. 47, 510-529. https://doi.org/10.1080/17475759.2018.1503192 
Courtright, C., 2005. Health information-seeking among Latino newcomers: An exploratory study. Inf. Res. 10, available at: http://www.informationr.net/ir/10-2/paper224.

Cox, C., Burgess, S., Sellitto, C., Buultjens, J., 2009. The role of user-generated content in tourists' travel planning behavior. J. Hosp. Mark. Manag. 18, 743-764. https://doi.org/10.1080/19368620903235753

ELLIS, D., 1989. A BEHAVIOURAL APPROACH TO INFORMATION RETRIEVAL SYSTEM DESIGN. J. Doc. 45, 171-212. https://doi.org/10.1108/eb026843

Entekhab, 2015. Viber Finally Got Filtered. URL https://www.entekhab.ir/fa/news/161368

Faraj, S., Azad, B., 2012. The materiality of technology: An affordance perspective., in: Leonardi, P.M., Nardi, B.A., Kallinikos, J. (Eds.), Materiality and Organizing: Social Interaction in a Technological World. OUP Oxford.

Forte, A., Dickard, M., Magee, R., Agosto, D.E., 2014. What do teens ask their online social networks?: Social search practices among high school students, in: Proceedings of the 17th ACM Conference on Computer Supported Cooperative Work \& Social Computing, CSCW '14. ACM, New York, NY, USA, pp. 28-37. https://doi.org/10.1145/2531602.2531723

Frenkel, S., 2018. Iranian authorities block access to social media tools. N. Y. Times Sect. Technol. ISSN 0362-4331.

Gibson, J.J., 2014. The Ecological Approach to Visual Perception: Classic Edition. Psychology Press, p. 347, ISBN: 978-1-317-57938-0.

Golkar, P., 2015. 5 Reasons to move from Viber to Telegram. URL https://web.archive.org/web/20180103133627/https://itresan.com/78795/viber-ortelegram/.html

Guberek, T., McDonald, A., Simioni, S., Mhaidli, A.H., Toyama, K., Schaub, F., 2018. Keeping a low profile?: Technology, risk and privacy among undocumented immigrants, in: Proceedings of the 2018 CHI Conference on Human Factors in Computing Systems, CHI '18. ACM, New York, NY, USA, p. 114:1-114:15. https://doi.org/10.1145/3173574.3173688

Hakim Silvio, D., 2006. The information needs and information seeking behaviour of immigrant southern Sudanese youth in the city of London, Ontario: An exploratory study. Libr. Rev. 55, 259-266. https://doi.org/10.1108/00242530610660807

Harper, F.M., Raban, D., Rafaeli, S., Konstan, J.A., 2008. Predictors of answer quality in online Q\&A sites, in: Proceedings of the SIGCHI Conference on Human Factors in Computing Systems, CHI '08. ACM, New York, NY, USA, pp. 865-874. https://doi.org/10.1145/1357054.1357191

Hirsch, T., Liu, J., 2004. Speakeasy: Overcoming barriers and promoting community development in an immigrant neighborhood, in: Proceedings of the 5th Conference on Designing Interactive Systems: Processes, Practices, Methods, and Techniques, DIS '04. ACM, New York, NY, USA, pp. 345-348. https://doi.org/10.1145/1013115.1013176

Horvat, S., 2015. The Radicality of Love | Wiley, ISBN: 978-0-745-69114-5.

Hossain, M.D., Veenstra, A.S., 2017a. The Uses and Gratifications of Language in Social Media among the Indian Subcontinental Diaspora in the U.S. J. Intercult. Commun. Res. 46, 478496. https://doi.org/10.1080/17475759.2017.1377101

Hossain, M.D., Veenstra, A.S., 2017b. Social capital and relationship maintenance: uses of social media among the South Asian Diaspora in the U.S. Asian J. Commun. 27, 1-17. https://doi.org/10.1080/01292986.2016.1240817

Hutchby, I., 2001. Technologies, Texts and Affordances. Sociology 35, 441-456. https://doi.org/10.1017/S0038038501000219

ISNA (2017), Telegram Consumes 60\% of the Country's Bandwidth. [WWW Document], n.d. URL https://www.isna.ir/news/96062715757/ 
Jafari, H., 2017. Telegram Channels Break the Record Number of Farsi Content over the Internet. TechRasa. URL http://techrasa.com/2017/08/13/telegram-channels-break-record-numberfarsi-content-internet/

Jeon, G.Y., Ellison, N.B., Hogan, B., Greenhow, C., 2016. First-generation students and college: The role of Facebook networks As information sources, in: Proceedings of the 19th ACM Conference on Computer-Supported Cooperative Work \& Social Computing, CSCW'16. ACM, New York, NY, USA, pp. 887-899. https://doi.org/10.1145/2818048.2820074

Kennan, M.A., Lloyd, A., Qayyum, A., Thompson, K., 2011. Settling in: The Relationship between Information and Social Inclusion. Aust. Acad. Res. Libr. 42, 191-210. https://doi.org/10.1080/00048623.2011.10722232

Kennedy, J.F., 1964. A nation of immigrants, Rev. and enl. ed. Introd. by Robert F. Kennedy. ed, Harper torchbooks: TB1118. Harper and Row.

Khodabakhshi, L., 2018. Why ordinary Iranians are turning to internet backdoors to beat censorship BBC News, Available at: https://www.bbc.com/news/blogs-trending-42612546.

Khoir, S., Du, J.T., Koronios, A., 2015. Everyday information behavior of Asian immigrants in South Australia: A mixed-methods exploration. Inf. Res. 20 No 3 Pap. 20.

Khojasteh, N., Fussell, S.R., 2017. Undergraduate students' preferences for friendsourcing on Facebook Vs. group messaging applications, in: Proceedings of the 2017 CHI Conference Extended Abstracts on Human Factors in Computing Systems, CHI EA '17. ACM, New York, NY, USA, pp. 1756-1762. https://doi.org/10.1145/3027063.3053133

Lambert, S.D., Loiselle, C.G., 2007. Health information-seeking behavior. Qual. Health Res. 17, 1006-1019. https://doi.org/10.1177/1049732307305199

Lampe, C., Vitak, J., Gray, R., Ellison, N., 2012. Perceptions of Facebook's value as an information source, in: Proceedings of the SIGCHI Conference on Human Factors in Computing Systems, CHI '12. ACM, New York, NY, USA, pp. 3195-3204. https://doi.org/10.1145/2207676.2208739

Lee, C.S., 2010. Managing perceived communication failures with affordances of ICTs. Comput. Hum. Behav., Emerging and Scripted Roles in Computer-supported Collaborative Learning 26, 572-580. https://doi.org/10.1016/j.chb.2009.12.009

Lloyd, A., 2020. Shaping the contours of fractured landscapes: Extending the layering of an information perspective on refugee resettlement. Inf. Process. Manag. 57, 102062. https://doi.org/10.1016/j.ipm.2019.102062

Lloyd, A., Wilkinson, J., 2019. Tapping into the information landscape: Refugee youth enactment of information literacy in everyday spaces. J. Librariansh. Inf. Sci. 51, 252-259. https://doi.org/10.1177/0961000617709058

López, G., Bialik, K., Radford, J., 2018. Key findings about U.S. immigrants. Pew Res. Cent. URL http://www.pewresearch.org/fact-tank/2018/09/14/key-findings-about-u-s-immigrants/ (accessed 9.20.18).

Maier, J.R.A., Fadel, G.M., 2009. Affordance based design: a relational theory for design. Res. Eng. Des. 20, 13-27. https://doi.org/10.1007/s00163-008-0060-3

Mamykina, L., Manoim, B., Mittal, M., Hripcsak, G., Hartmann, B., 2011. Design lessons from the fastest Q\&A site in the west, in: Proceedings of the SIGCHI Conference on Human Factors in Computing Systems, CHI '11. ACM, New York, NY, USA, pp. 2857-2866. https://doi.org/10.1145/1978942.1979366

Milano, R., Baggio, R., Piattelli, R., 2011. The effects of online social media on tourism websites, in: Law, R., Fuchs, M., Ricci, F. (Eds.), Information and Communication Technologies in Tourism 2011. Springer Vienna, Vienna, pp. 471-483. https://doi.org/10.1007/978-3-70910503-0 38

Aslib Journal of Information Management (C) Emerald Publishing, Limited 2050-3806 DOI 10.1108/AJIM-11-2019-0321 
Mitra, A., Evansluong, Q., 2019. Narratives of integration: Liminality in migrant acculturation through social media. Technol. Forecast. Soc. Change 145, 474-480. https://doi.org/10.1016/j.techfore.2019.01.011

Mobasher, M., 2006. Cultural Trauma and Ethnic Identity Formation Among Iranian Immigrants in the United States. Am. Behav. Sci. 50, 100-117. https://doi.org/10.1177/0002764206289656

Mostashari, A., Khodamhosseini, A., 2000. An Overview of Socioeconomic Characteristics of the Iranian-American Community based on the 2000 U.S. Census 8, Iranian Studies Group at MIT Available at: http://web.mit.edu/isg/PUBLICATIONS/socioeconomic.pdf.

Mostofi, N., 2003. Who We Are: The Perplexity of Iranian-American Identity. Sociol. Q. 44, 681703. https://doi.org/10.1111/j.1533-8525.2003.tb00531.x

Nikbakht Nasrabadi, A., Sabzevari, S., Negahban Bonabi, T., 2015. Iranian Women's Experiences of Health Information Seeking Barriers: A Qualitative Study in Kerman. Iran. Red Crescent Med. J. 17. https://doi.org/10.5812/ircmj.25156

Norman, D., 2013. The design of everyday things, Basic Books, ISBN : 9780465050659.

Oh, C., Butler, B.S., 2018. New international students' social information practices during transition to their host country. Proc. Assoc. Inf. Sci. Technol. 55, 879-880. https://doi.org/10.1002/pra2.2018.14505501157

Oh, C., Butler, B.S., Jean, B.St., 2018. Wandering as information behavior in new environments. Proc. Assoc. Inf. Sci. Technol. 55, 877-878. https://doi.org/10.1002/pra2.2018.14505501156

Oh, C.Y., Butler, B., 2019. Small worlds in a distant land: International newcomer students' local information behaviors in unfamiliar environments. J. Assoc. Inf. Sci. Technol. 70, 1060-1073. https://doi.org/10.1002/asi.24185

Panovich, K., Miller, R., Karger, D., 2012. Tie strength in question \& answer on social network sites, in: Proceedings of the ACM 2012 Conference on Computer Supported Cooperative Work, CSCW'12. ACM, New York, NY, USA, pp. 1057-1066.

https://doi.org/10.1145/2145204.2145361

Radford, J., Noe-Bustamante, L., 2019. Immigrants in America: Key charts and facts. Pew Res. Cent. Hisp. Trends Proj. URL https://www.pewresearch.org/hispanic/2019/06/03/facts-on-u-simmigrants/

Radio Farda, 2012. Iranian National Organization for Civil Registration: More than 2 million Iranians live in the U.S.A and the U.A.E (in Persian). Radio Farda.

Rao, X., Hemphill, L., 2016. Asian american chicago network: A case study of Facebook group use By immigrant groups, in: Proceedings of the 19th ACM Conference on Computer Supported Cooperative Work and Social Computing Companion, CSCW'16 Companion. ACM, New York, NY, USA, pp. 381-384. https://doi.org/10.1145/2818052.2869077

Sawyer, R., Chen, G.-M., 2012. The impact of social media on intercultural adaptation. Intercult. Commun. Stud. XXI, 151-169.

Shirazi, M., Champeau, D., Talebi, A., 2006. Predictors of breast cancer screening among immigrant Iranian women in California. J. Womens Health 2002 15, 485-506. https://doi.org/10.1089/jwh.2006.15.485

Shoham, S., Strauss, S.K., 2008. Immigrants' information needs: their role in the absorption process. Inf. Res. Vol. 13, No. 4.

Smith, B.B., 2013. Here's how Iran censors the Internet. Wash. Post.

Suh, M. (Mia), Hsieh, G., 2019. The "Had Mores": Exploring korean immigrants' information behavior and ICT usage when settling in the United States. J. Assoc. Inf. Sci. Technol. 70, 3848. https://doi.org/10.1002/asi.24078

Talhouk, R., Mesmar, S., Thieme, A., Balaam, M., Olivier, P., Akik, C., Ghattas, H., 2016. Syrian refugees and digital health in Lebanon: Opportunities for improving antenatal health, in: 
Proceedings of the 2016 CHI Conference on Human Factors in Computing Systems, CHI '16. ACM, New York, NY, USA, pp. 331-342. https://doi.org/10.1145/2858036.2858331

Tebyan, 2015. From Viber to Telegram. URL article.tebyan.net/296339/

Teevan, J., Alvarado, C., Ackerman, M.S., Karger, D.R., 2004. The perfect search engine is not enough: A study of orienteering behavior in directed search, in: Proceedings of the SIGCHI Conference on Human Factors in Computing Systems, CHI '04. ACM, New York, NY, USA, pp. 415-422. https://doi.org/10.1145/985692.985745

Vahabi, M., 2011. Breast cancer and screening information needs and preferred communication medium among Iranian immigrant women in Toronto. Health Soc. Care Community 19, 626635. https://doi.org/10.1111/j.1365-2524.2011.01004.x

Worrall, A., Ballantyne, E., Kendall, J., 2019. "You don't feel that you're so far away": Information sharing, technology use, and settlement of international student immigrants. Proc. Assoc. Inf. Sci. Technol. 56, 306-315. https://doi.org/10.1002/pra2.25

Zammuto, R.F., Griffith, T.L., Majchrzak, A., Dougherty, D.J., Faraj, S., 2007. Information Technology and the Changing Fabric of Organization. Organ. Sci. 18, 749-762. https://doi.org/10.1287/orsc.1070.0307

Received 12 November 2019 Revised 15 May 2020 Accepted 19 June 2020

Corresponding author Sarah Nikkhah can be contacted at: snikkhah@iu.edu

The current issue and full text archive of this journal is available on Emerald Insight at: https://www.emerald.com/insight/2050-3806.htm For instructions on how to order reprints of this article, please visit our website: www.emeraldgrouppublishing.com/licensing/reprints.htm Or contact us for further details: permissions@emeraldinsight.com 